\title{
Los sistemas de riego y el desarrollo agrícola en Aguascalientes durante el siglo XIX
}

JESÚS GÓMEZ SERRANO

Departamento de Historia/UAA

\section{RESUMEN}

\begin{abstract}
A partir de la caracterización de la región y la descripción de los tres sistemas de irrigación empleados -pequeños aguajes, grandes presas de mampostería y utilización de aguas freáticas-, el artículo discute la importancia de la irrigación y el carácter limitado de los progresos que se registraron en ese renglón durante el siglo XIX. Ni los hacendados ni el gobierno fueron capaces de acometer mejoras verdaderamente importantes, lo que explica en parte el atraso de la agricultura. A pesar de la importancia que se le concedía, el proyecto de construir una gran presa que irrigara el valle de Aguascalientes nunca pudo concretarse.
\end{abstract}

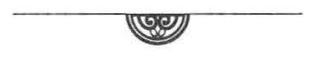

ABSTRACT

THE SYSTEMS OF IRRIGATION AND THE AGRICULTURAL DEVELOPMENT IN AGUASCALIENTES DURING THE NINETEENTH CENTURY

This article arguments the importance of the irrigation and the limited nature of the progresses that took place in the region during the Nineteenth century.

The landholders and the governments were incapable of doing truly improvements, which explains somehow the backwardness of the agriculture. In spite of the its conceded importance, the project of building a big dam which would irrigate the Aguascalientes valley, it never could be done. 
F

in su artículo sobre la construcción de la presa Calles y el distrito de riego número 1, en el valle de Aguascalientes, Edgar Hurtado hizo algunas observaciones sobre la importancia que concedían los agricultores y los promotores oficiales del desarrollo agrícola a la construcción de grandes sistemas de irrigación que garantizaran el éxito de las cosechas. ${ }^{1}$

El propósito de estas líneas es continuar el diálogo propuesto por Hurtado y ampliar los horizontes históricos de la discusión sobre el riego y su relación con el desarrollo agrícola regional. Después de caracterizar someramente la región, su régimen pluviométrico y la importancia crucial de las lluvias, hablaremos de los grandes sistemas de irrigación empleados durante el siglo XIX y del carácter limitado de los avances que en este terreno experimentó la agricultura. Esa discusión nos permitirá colocar en su adecuado contexto el proyecto frustrado de construir la grandiosa presa de Santiago, que como ya señaló Hurtado constituye un antecedente directo de la presa Calles, construida entre 1926 y 1927. Como se verá, la falta de sistemas de riego modernos y eficientes es uno de los factores que explican la forma perezosa en que se desarrolló la agricultura durante el siglo XIX.

\section{La región y su régimen pluviométrico}

Desde el punto de vista geológico es notable que el valle de Aguascalientes divide al estado en dos partes casi iguales. La mitad oriental forma parte de la provincia geológica de la Mesa Central y sus formaciones rocosas más importantes provienen del periodo terciario; la otra mitad forma parte de la provincia de la Sierra Madre Occidental y su estratigrafía revela la existencia de pequeños afloramientos

\footnotetext{
' Edgar Hurtado Hernández, "El distrito de riego 01 y el desarrollo de la agricultura en Aguascalientes, 1925-1935", en Caleidoscopio, núm. 3, enero-junio de 1998, pp. 89-113.
} 
que datan del periodo jurásico, es decir, de una edad geológica anterior a la que cubre el periodo terciario. A estas provincias principales debe agregarse la del Eje Neovolcánico, que hace por el sur una pequeña penetración en territorio del estado de Aguascalientes. Carlos Ortega ha caracterizado el estado como una "zona de transición" entre la altiplanicie meridional, que comprende los estados de Guanajuato, Querétaro y el Distrito Federal, así como partes de los de Zacatecas, Michoacán, Hidalgo y Jalisco, y la altiplanice septentrional, que abarca los estados de Coahuila, Chihuahua y Durango, así como la mayor parte del de Zacatecas. ${ }^{3}$

El valle de Aguascalientes se encuentra a una altitud promedio de 1,800 m. sobre el nivel del mar, aunque en las partes más altas de la Sierra Fría, que divide por el poniente el estado del de Zacatecas, se rebasan ligeramente los 3 mil m. (la mayor altura se encuentra en el cerro de La Ardilla, con 3,050 m.). El valle de Huejúcar, que forma una pequeña pero bien definida depresión delimitada por la Sierra Fría y la Sierra del Laurel, tiene casi la misma altura que el de Aguascalientes, aunque un poco más al sur, en Jalpa, se desciende hasta los 1,450 m. En sus puntos más altos (el cerro de La Antorcha y el de los Díaz), la Sierra del Laurel alcanza los 2,800 m. $\mathrm{Al}$ oriente, las mesas que pasarían a formar parte del latifundio de Ciénega de Mata se encuentran a una altitud media de 2,200 m, con algunas prominencias (el cerro del Espía y la mesa del Toro) que alcanzan los $2,700 \mathrm{~m}^{4}{ }^{4}$

\footnotetext{
${ }^{2}$ Sintesis geográfica de Aguascalientes, México, Secretaría de Programación y Presupuesto, 1981, pp. 17-22.

${ }^{3}$ Carlos Enrique Ortega de León, Estudio geoeconómico de Aguascalientes, tesis de licenciatura en economía, UNAM, 1977, pp. 21-25. (Para una detallada caracterización geológica del estado puede verse el capítulo 3 de este mismo trabajo, pp. 61-75.)

${ }^{4}$ Además del mapa de regionalización fisiográfica publicado en la Síntesis geográfica de Aguascalientes (pp. 44 y 63), puede verse la carta geográfica en relieve publicada por el INEGI en 1991. También pueden consultarse con provecho las pp. 13-21 del Estudio geoeconómico de Aguascalientes, de Carlos Ortega, donde se detallan y ubican las principales prominencias topográficas del estado.
} 
La temperatura media anual que se registra en el estado oscila en torno a los $17 / 18^{\circ} \mathrm{C}$. Las temperaturas mínimas se registran en enero, con valores de $13^{\circ} \mathrm{C}$ en promedio, y las más altas en junio, cuando el termómetro promedia valores cercanos a los $25^{\circ} \mathrm{C} .{ }^{5} \mathrm{Apo}-$ yado en datos recogidos en la estación climatológica de Malpaso, en Calvillo, Carlos Ortega hizo notar un descenso de la temperatura media del orden del $0.1^{\circ} \mathrm{C}$ anual, lo que entre 1950 y 1972 llevó el registro medio de $20.5^{\circ} \mathrm{C}$ a $17.4^{\circ} \mathrm{C}$. Este cambio se atribuye al desarrollo de los cultivos frutícolas y se identifica a la evapotranspiración de los árboles frutales como el agente causal del descenso de la temperatura. ${ }^{6}$ Por otra parte, es interesante advertir que en general el clima parece haberse vuelto mucho más extremoso, sobre todo en la estación cálida, en la que el termómetro alcanza con alguna frecuencia los $40^{\circ} \mathrm{C} .{ }^{7} \mathrm{Si}$ tomamos como referencia los registros que hizo el Ing. Miguel Velázquez de León en su hacienda de Pabellón en 1873, año en el que la máxima temperatura que se alcanzó fue de $30^{\circ} \mathrm{C},{ }^{8}$ tendremos una idea de la magnitud de los cambios que se han operado en el clima de la región. Las perturbaciones son aún más dramáticas si advertimos que se han operado en un lapso de sólo un siglo, insignificante en términos de la edad del planeta y del sistema del que forma parte.

La precipitación pluvial en el estado promedia unos $540 \mathrm{~mm}$ anuales, registrándose la variación más importante en la sierra del Laurel, dentro del municipio de Calvillo, y en las partes altas de la Sierra Fría, donde se acumulan poco más de $600 \mathrm{~mm}$ al año de agua y el clima en general es más templado y húmedo. Es notable

${ }^{5}$ Sintesis geográfica de Aguascalientes, p. 15.

${ }^{6}$ C. Ortega, Estudio geoeconómico de Aguascalientes, p. 39.

${ }^{7}$ El máximo valor registrado fue de $44^{\circ} \mathrm{C}$, en la estación de San Bartolo, en agosto de 1952. (C. Ortega, Estudio geoeconómico de Aguascalientes, p. 36.)

8 "Resumen de las temperaturas medidas (sic por medias) mensuales y anuales observadas en la hacienda de Pabellón, del estado de Aguascalientes, durante el año de 1873", en El Republicano, 19 de marzo de 1874. 
que las lluvias se concentran entre los meses de junio y septiembre, extendiéndose el estiaje, que por regla general es muy riguroso, desde mediados de octubre hasta fines de mayo. La mayor incidencia de lluvias se da en los meses de julio y agosto, en cada uno de los cuales el pluviómetro registra precipitaciones acumuladas de 120/130 mm. ${ }^{9}$ Este patrón de distribución de las lluvias, al que se añaden las fuertẹs y continuas heladas que se presentan desde fines de noviembre hasta principios de marzo, constituye una condicionante de la mayor importancia para las prácticas agrícolas. ${ }^{10}$

De hecho, en toda la meseta central del país los índices de precipitación pluvial son incapaces de asegurar el éxito de los cultivos de temporal. A la escasez y la irregularidad de las lluvias debe agregarse la temible evaporación, que durante el verano es muy alta a causa del calor. Según Claude Bataillón, en esas condiciones las siembras de maíz y frijol necesitarían un mínimo de $700 \mathrm{~mm}$ de agua para lograrse. Si en el corazón del Bajío ello no se da, mucho menos en su extremo septentrional, en la región agrícola de Aguascalientes, donde el calor es un poco más fuerte y las lluvias más escasas e irregulares. De esta manera, la idea misma de un cultivo de temporal está asociada a la inseguridad. ${ }^{11}$

Como resultado de la altura sobre el nivel del mar, la temperatura, la precipitación pluvial y la evaporación potencial, los climas dominantes en el estado de Aguascalientes son del tipo estepario o

${ }^{9}$ Síntesis geográfica de Aguascalientes, pp. 15-16; C. Ortega, Estudio geoeconómico de Aguascalientes, pp. 40-52, particularmente el cuadro de la p. 45, donde se resumen las precipitaciones medias mensuales registradas en las 29 estaciones climatológicas del estado.

${ }^{10}$ En un ensayo reciente se ha sugerido que, como probable efecto del aumento de la temperatura del planeta, la precipitación pluvial ha aumentado en Aguascalientes unos $120 \mathrm{~mm}$ durante los últimos 50 años. (Joaquín Sosa Ramírez, Agua y sustentabilidad en Aguascalientes. Tres ensayos, Aguascalientes, CIEMA/Gobierno del Estado, 1998, pp. 1-36.)

${ }^{1}$ C. Bataillon, Las regiones geográficas en México, México, Siglo XXI Editores, 1969, p. 161. 
semidesértico y del templado subhúmedo, extremosos en ambos casos, pues las temperaturas medias mensuales oscilan entre los 7 y los $14^{\circ} \mathrm{C}$. El clima templado subhúmedo sólo se registra en las partes altas de la Sierra Fría y la Sierra del Laurel, siendo los climas esteparios los dominantes en la inmensa mayoría de la superficie estatal, lo que contribuye a explicar las escasas posibilidades de éxito que ha tenido siempre la agricultura de temporal. ${ }^{12}$

Con excepción del municipio de Calvillo, el estado forma parte de la cuenca hidrológica del río Verde, del cual son tributarios el San Pedro o Aguascalientes, el Chicalote, el Encarnación y el Morcinique. La subregión de Calvillo, por su parte, está drenada por el río Juchipila, que conforma otra cuenca hidrológica. Tanto el río Verde como el Juchipila son afluentes del Lerma-Santiago y forman parte de esa región hidrológica. Por su caudal, el más importante de los pequeños ríos del estado es el San Pedro, que aún antes de la construcción de presas y bordos se secaba por completo durante el estiaje. Este río se forma en el valle de Ojocaliente, al sur de Zacatecas, con pequeños escurrimientos que corren de norte a sur y que atraviesan todo el municipio de Rincón de Romos. Ahí se enriquece notablemente su caudal gracias a la confluencia de los ríos de Pabellón y Santiago, a los que se añaden otros escurrimientos menores que bajan de la Sierra Fría. Muy cerca del antiguo pueblo de indios de Jesús María, en el corazón del valle de Aguascalientes, el río Chicalote une su caudal al San Pedro, permitiéndole a éste alcanzar la mayor amplitud y profundidad de todo su trayecto. Después de rodear por el poniente la ciudad de Aguascalientes, el río San Pedro sigue corriendo hacia el sur, hasta unirse, cerca de Teocaltiche, al río Verde. ${ }^{13}$

${ }^{12}$ C. Ortega, Estudio geoeconómico de Aguascalientes, pp. 52-59.

${ }^{13}$ Ibid., pp. 83-84. 
La insuficiencia de las aguas superficiales se ve ligeramente compensada por las subterráneas, muy abundantes en los valles de Aguascalientes y Calvillo e indispensables tanto para el desarrollo de la agricultura como para el consumo humano. ${ }^{14}$ De hecho, el manantial del Ojocaliente fue capaz de satisfacer los requerimientos de agua de la villa a lo largo de toda la época colonial. Como veremos, sería hasta fines del siglo XIX cuando el desarrollo tecnológico permitió un aprovechamiento más sistemático de estos veneros.

Irregularidad e insuficiencia de las lluvias

Aunque abundan las quejas sobre la insuficiencia y el caprichoso carácter de las lluvias, contamos con muy pocas registros que nos permitan establecer con exactitud los niveles de precipitación que había en la región. Para la época colonial, sólo contamos con algunos intentos aislados y más bien impresionistas de caracterizar el régimen pluviométrico de la región. Domingo Lázaro de Arregui, por ejemplo, observó en 1621 lo siguiente:

el tiempo de aguas... empieza por fin de mayo... (y) son tan continuas que desde el tiempo dicho hasta principio de octubre todos los días, en pasando el sol de nuestro meridiano, se juntan o engruesan los nublados y empieza a llover con grandes truenos. ${ }^{15}$

Los primeros registros metódicos y confiables que conocemos son los que hizo Miguel Velázquez de León en la época de la República Restaurada. Antiguo profesor del Colegio de Minería, Velázquez de León instaló en su hacienda de Pabellón un pequeño observatorio en el que durante varios años llevó un cuidadoso re-

\footnotetext{
14 Síntesis geográfica de Aguascalientes, pp. 23-28; C. Ortega, Estudio geoeconómico de Aguascalientes, pp. 92-100.

${ }^{15}$ Domingo Lázaro de Arregui, Descripción de la Nueva Galicia, Guadalajara, edición del Gobierno del Estado de Jalisco, 1980, pp. 85-86.
} 
gistro no sólo de la precipitación pluvial, sino también de la temperatura y los rendimientos de sus cultivos. No conocemos y es muy probable que no se conserven en ningún archivo los cuadernos en los que el Ing. Velázquez de León hacía sus anotaciones, pero por suerte se publicaron en un periódico local unos cuadros en los que se resumen algunos registros. ${ }^{16}$

Precipitación pluvial (mm.) en la hacienda de Pabellón, 1869-1873

\begin{tabular}{|c|r|r|r|r|r|}
\hline Meses & 1869 & 1870 & 1871 & 1872 & 1873 \\
\hline Enero & 20.5 & 4.5 & 12.5 & 0.0 & 1.5 \\
Febrero & 0.0 & 0.0 & 0.0 & 0.0 & 0.0 \\
Marzo & 13.6 & 0.0 & 0.0 & 0.0 & 0.0 \\
Abril & 0.0 & 0.0 & 0.0 & 0.0 & 0.0 \\
Mayo & 4.8 & 6.9 & 0.0 & 45.4 & 0.0 \\
Junio & 47.6 & 259.5 & 121.6 & 78.6 & 110.0 \\
Julio & 161.9 & 154.7 & 64.1 & 68.4 & 147.0 \\
Agosto & 69.3 & 216.2 & 86.2 & 60.6 & 81.0 \\
Septiembre & 206.3 & 123.6 & 88.0 & 66.3 & 90.5 \\
Octubre & 86.5 & 50.0 & 0.2 & 28.0 & 11.5 \\
Noviembre & 0.0 & 26.1 & 0.0 & 3.6 & 26.5 \\
Diciembre & 0.0 & 0.0 & 0.0 & 0.0 & 17.0 \\
\hline Totales & 610.5 & 841.5 & 372.6 & 350.9 & 485.0 \\
\hline
\end{tabular}

Fuente: Miguel Velázquez de León, "Lluvias medidas en la hacienda de Pabellón durante los años que se expresan”, en El Republicano, 19 de marzo de 1874.

${ }^{16}$ Además de los registros de temperatura ya citados, véase el cuadro titulado "Lluvias medidas en la hacienda de Pabellón durante los años que se expresan" (1869-1873), publicado en El Republicano, 19 de marzo de 1874. 
Estas mediciones confirman el carácter errático e insuficiente de las lluvias. De los 5 años registrados, sólo en uno la precipitación rebasó el nivel de $700 \mathrm{~mm}$. que Bataillon define como mínimo para asegurar el éxito de un cultivo de temporal. En un año las lluvias sólo alcanzaron los $350 \mathrm{~mm}$. y en otro $372 \mathrm{~mm}$., lo que ciertamente debió provocar la ruina de los cultivos. En todo el quinquenio 1869-1873 el Ing. Velázquez de León registró una acumulación pluvial de $2655 \mathrm{~mm}$., lo que arroja un promedio anual de $531 \mathrm{~mm}$., muy por debajo de lo que necesitaban el maíz o el frijol de temporal para lograrse.

Aparte de insuficientes, las lluvias eran muy caprichosas. Sólo el año de 1870 parece haber respondido cabalmente a las expectativas de los labradores, pues la lluvia llegó a su tiempo y en las cantidades necesarias. Prácticamente no cayó una gota de agua entre enero y abril, lo que permitió que el invierno hiciera su parte y acabara con las plagas; empezó a llover un poco en mayo, lo que facilitó las siembras; luego, durante los meses cruciales de junio, julio y agosto, época en la que las plantas crecen, sazonan y dan su fruto, las lluvias tuvieron una regularidad asombrosa. Incluso casi dejó de llover en septiembre, lo que evitó que el grano se pudriera por exceso de humedad o que los encharcamientos dificultaran la recolección. Pero de todo el periodo que cubren las observaciones de Velázquez de León, ése fue el único año en el que el cielo se apiadó de los labradores; en todos los demás las lluvias fueron insuficientes y además llegaron a destiempo. El año de 1869, por ejemplo, no fue del todo malo (610 mm.), pero las lluvias, escasas a lo largo de todo el verano, arreciaron en septiembre, cuando ya era demasiado tarde.

Como era de esperarse en un estado eminentemente agrícola como Aguascalientes, las veleidades del temporal provocaban toda clase de desgracias. Unas veces la falta de agua, otras su exceso, pero eran raros los años en los que se podían levantar buenas cosechas. A mediados de septiembre de 1904, por ejemplo, se reportaba 
que había llovido en abundancia, pero que ello no había dejado de ocasionar perjuicios en los campos donde los suelos eran muy delgados y los consiguientes encharcamientos habían provocado la pérdida de las cosechas. ${ }^{17}$ En mayo del año siguiente se hablaba del "verdadero desconcierto atmosférico que se ha registrado" y de las "considerables" pérdidas ocasionadas a las sementeras. Unas heladas muy tardías provocaron "la pérdida y ruina total" de las siembras de chile y causaron daños muy serios a las hortalizas. Los agricultores más viejos aseguraban que nunca habían visto tales "irregularidades atmosféricas". ${ }^{18}$

En 1910 las lluvias fueron escasas e irregulares; quienes hicieron sus siembras muy temprano lamentaron la falta de agua en "el periodo más crítico" del desarrollo de las plantas y quienes lo hicieron tarde fueron sorprendidos por los primeros fríos, que llegaron cuando las plantas no acababan todavía de madurar. ${ }^{19} \mathrm{Al}$ año siguiente "las precipitaciones vinieron con toda oportunidad" y los campos presentaban a principios de verano "un aspecto muy halagador", pero en julio dejó de llover y las primeras siembras se perdieron por completo. Sólo quienes sembraron hasta el último momento se beneficiaron con las lluvias de fines de octubre y principios de noviembre. Pero esas mismas aguas tardías, buenas para el maíz y el frijol, arruinaron los cultivos de chile. En resumen, se calculaba que durante ese año se había perdido el $60 \%$ de las cosechas..$^{20} \mathrm{El}$ año de 1913 fue muy llovedor y se levantaron buenas co-

${ }^{17}$ Boletín de la Sociedad Agrícola Mexicana, tomo XXVIII, núm. 35, 17 de septiembre de 1904, p. 700.

${ }^{18}$ Boletín de la Sociedad Agrícola Mexicana, tomo XxIX, núm. 17, 1 de mayo de 1905 , p. 320.

19 "Inconstancia de las nubes", El Clarín, 22 de octubre de 1910.

20 "Informe sobre las condiciones de la agricultura en el estado de Aguascalientes durante el periodo comprendido entre el 1 de diciembre de 1910 y el 30 de noviembre de 1911", en Boletín mensual de la Cámara Agrícola Nacional de Aguascalientes, tomo I, núm. 10, 1 de enero de 1912, pp. 2-3. 
sechas de maíz, frijol, trigo y chile, pero en los lugares en los que los suelos eran muy delgados la misma abundancia de agua provocó pérdidas de consideración. ${ }^{21}$

\section{Sistemas de irrigación}

Fueron 3 los recursos utilizados por los agricultores de la región para contrarrestar los efectos del incierto temporal. ${ }^{22}$ En primer lugar, los pequeños bordos o cajas de agua, mucho más útiles de lo que sugieren las apariencias, pues aparte de su bajo costo permitían irrigar pequeñas parcelas y servían como abrevaderos para el ganado. En seguida, las grandes presas de mampostería, características de las haciendas más ricas pero escasas pese a todo, pues su costo era muy elevado y el terreno no siempre ofrecía los relieves que permitieran la formación de los vasos o depósitos. Además, los efectos de la evaporación en el verano eran temibles. Durante la segunda mitad del siglo XIX se introdujo poco a poco un tercer sistema de irrigación, consistente en el bombeo de las aguas freáticas; aunque los primeros pozos artesianos que se excavaron no tuvieron mucho éxito, la importación de máquinas perforadoras por parte de las empresas petroleras permitió que se hicieran nuevos intentos, que en muchos casos resultaron exitosos.

Al reparar en el carácter crucial de la irrigación, que desde 1827 había sido definida por el viajero inglés Henry George Ward como "el gran objetivo de la agricultura", ${ }^{23}$ puede sorprender el número relativamente corto de grandes presas que se construyeron en

\footnotetext{
${ }^{21}$ Informe de la CANA publicado en El Eco de San Luis, 24 de octubre de 1913.

${ }^{22}$ Seguimos el esquema de sistemas de irrigación propuesto por Bataillon para todo el Bajío. (Las regiones geográficas de México, p. 167.)

${ }^{23}$ Henry George Ward, México en 1827, México, Fondo de Cultura Económica, 1981, p. 53.
} 
la región. Si los aguajes eran tan importantes y le daban a las haciendas buena parte de su potencial productivo, ¿por qué parecen tan tímidas las inversiones destinadas a ello? ¿Debemos pensar que los propietarios no veían con claridad su propia conveniencia o que, como muchas veces se ha dicho, preferían despilfarrar sus recursos en obras suntuosas e improductivas? Desde luego el alto costo de esas obras representaba un problema que sólo podían enfrentar los propietarios más ricos, que contaban con los recursos necesarios o que tenían a la mano el crédito eclesiástico.

Sin embargo, el principal obstáculo no era financiero sino técnico, pues la constitución misma del terreno imponía limitaciones que no era nada fácil superar. La falta de grandes relieves impedía encontrar un paraje adecuado para el levantamiento de la cortina o bordo principal. De hecho es interesante advertir que las haciendas de Pabellón, Paredes, Santiago y El Saucillo, replegadas sobre las estribaciones de la Sierra Fría, eran las que contaban con las presas más grandes. En los suelos más parejos del llano del Tecuán o el valle central de Aguascalientes hubiera sido necesario construir cortinas inmensas para formar vasos capaces de contener, por extensión, grandes volúmenes de agua. Aún así, esos recipientes no contarían con los escurrimientos de la sierra y a cambio resentirían los terribles efectos del calor veraniego, todo lo cual los habría vuelto prácticamente inútiles.

De esta manera, la alternativa que tenían a mano la mayor parte de los propietarios era la de aprovechar, mediante pequeños bordos o elevaciones, los vasos naturales que se formaban en sus terrenos. A veces sucedía que estas "cajas de agua" eran más útiles que las costosas presas de calicanto, debido sobre todo a la relativa facilidad con la que podían acondicionarse. Al aludir a este problema, el Ing. Velázquez de León hizo notar la frecuente desproporción entre la utilidad real de las obras de riego y su costo: al lado de grandes depósitos naturales aprovechables mediante sencillas obras de ingeniería y pequeñas inversiones había presas de calicanto en las 
que se invertían "muchos miles de pesos", con las que, sin embargo, sólo se regaban "unas cuantas fanegas".

\section{Las presas de las grandes haciendas}

De cualquier manera, lo que queda claro es que los sistemas de riego constituían la mejora más importante y costosa de las haciendas de la región. De hecho sería fácil clasificar las haciendas por sus aguajes y constatar que las más ricas eran las que contaban con mejores sistemas de riego. A lo largo de la época colonial, pero sobre todo durante el siglo XVIII, se construyeron las presas más importantes, con cortinas de calicanto que medían por lo menos 100 varas de largo. Junto con la casa grande, la iglesia, las trojes, el molino y la cuadrilla formada por las chozas de los peones, la presa y los canales habilitados para la conducción de las aguas eran una de las mejoras indispensables del sitio principal de la hacienda, que con frecuencia le daba nombre a la hacienda. En las fincas más prósperas era frecuente que a esas primeras presas se añadieran después otras, que facilitaban el cultivo de los ranchos dependientes, muchas veces considerablemente alejados del principal centro de operaciones. El sitio de San Isidro Garabato, dependiente de la hacienda de Pabellón, contaba por lo menos desde mediados del siglo XVIII con una gran presa de mampostería valuada en 10 mil pesos. $^{25}$

A principios de la época independiente la hacienda de San Diego de la Labor contaba con 3 presas importantes, la mayor de

${ }^{24}$ Miguel Velázquez de León, "Informe sobre la hacienda de Pabellón" (28 de agosto de 1877), en Emiliano Busto, Estadística de la República Mexicana, México, 1880 , tomo III, p. 7.

${ }^{25}$ Véase el inventario de la hacienda practicado a la muerte de Lucas López de Fonseca en Archivo Histórico del Estado de Aguascalientes (en lo sucesivo, AHEA), Fondo de Protocolos Notariales, Not. Manuel Rafael de Aguilera, 1762, s.n., 97-129. 
las cuales tenía una cortina de 172 varas de largo, 3 y media de ancho y 11 y media de alto en el centro. En los inventarios se asignó a la presa un valor de poco más de 12 mil pesos, es decir, el 13.6\% del valor de la finca. De hecho, las presas, tomas de agua, acequias y demás obras hidráulicas de la hacienda tenían en inventarios un valor de casi 32 mil pesos, equivalentes al $36 \%$ del valor de la hacienda, lo cual habla con elocuencia del carácter crucial de estas mejoras. ${ }^{26} \mathrm{Y}$ todo ello sin considerar que se trata de una hacienda, como vimos un poco antes, que sólo tenía abiertos a la labor el $3.5 \%$ de sus tierras.

En Pabellón se contaba con una presa "fabricada en el río que atraviesa por la mitad" el sitio principal de la hacienda. La cortina medía 105 varas de largo, 6 y media de ancho y 12 y media de alto. Contaba además con un complejo sistema de vertederos, acequias y registros que llevaba el agua hasta las tierras de riego. La presa debió ser construida a principios del siglo XVIII y aunque no sabemos cuánto costó nos podemos dar una idea de su importancia si reparamos en que era la mejora más considerable del sitio principal de la hacienda, el cual tenía en inventarios un valor de 23,100 pesos. ${ }^{27}$

En la hacienda de Peñuelas la presa de Guadalupe, junto con sus acequias, tenía un valor de casi 23 mil pesos. Además estaban las presas de El Refugio y Las Huertas, más pequeñas que la anterior, y la de San Nicolás, "perteneciente al rancho de San Antonio". Por aparte se consideraron en los inventarios unas "cortinas de calicanto que hacen variar el curso de los arroyos para dirigirlos a las presas" y las arquerías que permitían a las acequias vadear esos arroyos. Todas estas obras tenían en 1867 un valor de 47,480 pesos, muy considerable en sí mismo y equivalente a casi la tercera

\footnotetext{
${ }^{26}$ El inventario de la hacienda en AHEA, Fondo del Poder Judicial, Sección Civil, 1845, 2.

${ }^{27}$ El inventario en AHEA-FPN, Not. Manuel Rafael de Aguilera, 1762, s.n., 97-129.
} 
parte de lo que valían la hacienda de Peñuelas y sus ranchos anexos de San Antonio y Buenavista. ${ }^{28}$

La hacienda de Ciénega Grande contaba con las presas de Ojo Zarco, Víboras, Coyotes y Viudas, todas muy pequeñas. Los terrenos que socorrían con riego alcanzaban una superficie de 40 fanegas de sembradura. Además había 4 estanques, que abastecían de agua la casa principal, el molino y uno de los ranchos dependientes. En el inventario de 1874 no se asignó valor a estas obras, "por estar ya contenido en el de los terrenos que riegan". ${ }^{29}$ En contrapartida, la hacienda de Natillas sólo contaba con una presa, valuada en 8,350 pesos y con una capacidad de almacenamiento de 1.1 millones de metros cúbicos de agua. ${ }^{30}$

El sitio principal de la hacienda de Cieneguilla, por su parte, contaba con una presa de calicanto de 206 varas de largo, 11 de alto y 6 de grueso, que regaba una gran labor de trigo de 25 cargas. Además, en el sitio de La Labor Vieja estaba la presa del Tarai, con una cortina de 220 varas de largo y capaz de abastecer de agua una labor de 12 cargas de trigo. ${ }^{31}$ A ello se añadían algunos ojos de agua y muchos riachuelos que sólo llevaban agua en la época de lluvias, pero que mediante pequeños diques eran aprovechados "para que los ganados tengan más agua y la beban con más comodidad". No

\footnotetext{
${ }^{28}$ Inventario de la hacienda levantado por el agrimensor José María Villalobos en septiembre de 1867, en AHEA-FPN, Not. Tranquilino Mercado, apéndice al protocolo de ese año, s.f.

29 "Inventario practicado por el albacea de común acuerdo con los herederos de los finados señores don Gil Rangel y doña María García de Rangel", en AHEA-FPN, Not. Candelario Medina, 1874, s.n., 210-244.

${ }^{30}$ El inventario de la hacienda en AHEA-FPN, Not. Alberto M. Dávalos, apéndice al protocolo de 1893, s.f. El dato de capacidad está tomado de la Síntesis geográfica de Aguascalientes, p. 75.

${ }^{31}$ Actualmente la importancia de las presas se mide por su capacidad, expresada en metros cúbicos de agua. Por desgracia, es imposible estimar, con la información que tenemos, la capacidad de la mayor parte de las presas y aguajes que había en las haciendas de la región.
} 
sabemos cuánto valían exactamente las presas, pero es muy revelador el hecho de que los sitios que contaban con esa clase de mejoras eran los más importantes de toda la finca. ${ }^{32}$

Al parecer, la presa más grande que había en Aguascalientes era la de la hacienda del Saucillo, construida en el siglo XVIII y con una capacidad de 6 y medio millones de metros cúbicos de agua..$^{33}$ Aunque el Ing. Velázquez de León sugirió en 1877 que esa gran obra era hasta cierto punto inútil, pues sólo se llenaba "cada 6 o 7 años", los dueños de la finca afirmaban que se trataba de una mejora fundamental, pues con sus aguas se regaban 350 fanegas de maíz, trigo, chile, garbanzo, lenteja y avena. ${ }^{34}$

Al lado de estas grandes presas, que sólo podían costearse en las haciendas más ricas de la región, había muchas presas pequeñas pero muy útiles, como las de las haciendas del Morcinique, Gracias a Dios, Chichimeco y San Bartolo. En la hacienda de Las Trojes había una, construida sobre el curso del río San Pedro pero cuyas acequias invadieron en parte las tierras de los indios de Jesús María, lo que no dejó de originar múltiples diferencias.

Todas las haciendas importantes de la región contaban al menos con una presa de calicanto y con varios bordos o cajas de agua, destinadas unas veces al riego y otras al abrevadero de los ganados. Según Isidoro Epstein, en 1861 había un total de 34 presas en Aguas-

\footnotetext{
${ }^{32}$ Avalúo de la hacienda de Cieneguilla (1771), en Archivo General de la Nación, Tierras, vol. 3284, fojas 15f-33v.

${ }^{33}$ Comparada con la capacidad de los grandes sistemas de riego actuales, la capacidad de esta presa resulta ínfima. Tan sólo la presa Presidente Calles, construida en 1926 y cuyo vaso cubrió el antiguo pueblo de indios de San José de Gracia, tiene una capacidad de 340 millones de metros cúbicos. Sin embargo, habría que aclarar que esa gran presa, que forma la columna vertebral del distrito de riego núm. 1, casi nunca se ha llenado; en 1981, por ejemplo, sólo tenía 11.5 millones de metros cúbicos de agua, es decir, el 3.4\% de su capacidad. (Síntesis geográfica de Aguascalientes, p. 75)

${ }^{34}$ Directorio comercial de Aguascalientes, 1908, p. 2. (Hay que aclarar que se trataba de una inserción hecha con fines publicitarios.)
} 
calientes, la más importante de las cuales era la de la hacienda del Saucillo. Esa cifra incluye las presas propiamente dichas, que contaban con una cortina de calicanto, y los simples bordos que muchas veces carecían de revestimiento, pese a lo cual reportaban un gran provecho a sus dueños. Por aparte Epstein dejó constancia de la existencia de una laguna en la hacienda del Saucillo y 2 más en la de Pabellón. ${ }^{35}$

\section{Nuevas presas}

Algo que debe subrayarse es que durante la mayor parte del siglo XIX casi no se hicieron grandes inversiones en sistemas de riego. Las haciendas se quedaron con las viejas presas de la época colonial y muchas veces ni siquiera tuvieron recursos para darles el debido mantenimiento. De hecho, en los inventarios abundan las referencias a las cortinas dañadas o reventadas que sencillamente no eran reparadas. En un inventario de la hacienda de Ciénega Grande practicado en 1874, por ejemplo, se decía que la presa de Ojo Zarco, "cuando tiene agua", daba riego a 10 fanegas de sembradura, pero que "en la actualidad no tiene por haberse reventado". ${ }^{36}$

Una notable excepción a esta regla es la presa de Malpaso, cerca de Calvillo, perteneciente a la hacienda del Sáuz y adquirida hacia 1840 por los hermanos José María y Raymundo Velasco. A fines de siglo, después de varias ampliaciones de su cortina, su capacidad de almacenamiento alcanzaba los 6 millones de metros cúbicos, lo que permitía irrigar una superficie de mil hectáreas. ${ }^{3 i}$ Lo más interesante es que esta presa no regaba las tierras de una hacienda, sino las de un gran número de pequeños y medianos agricultores inde-

35 Isidoro Epstein, Cuadro sinóptico de Aguascalientes, Aguascalientes, Tipografía Avila y Chávez, 1861.

3* El inventario en AHEA-FPN. Not. Candelario Medina, 1874, s.n., 210-244.

${ }^{3:}$ Datos de la Síntesis geográfica de Aguascalientes, p. 75. 
pendientes. De hecho, el éxito de la agricultura que se desarrolló en el valle de Huejúcar puede atribuirse, por lo menos en parte, a la existencia de esta mejora y a la fórmula que encontraron sus dueños para aprovecharla, ${ }^{38}$ los cuales constituyeron en 1907 la Compañía Explotadora de la Presa de Malpaso. ${ }^{39}$

- Un caso parecido es el de Enrique Farjou y José Bolado, dueños de 2 de los ranchos formados en tierras de la hacienda de La Cantera, quienes construyeron hacia 1880 la presa de El Niágara, en el curso del río San Pedro. ${ }^{40}$ En 1885 la cortina fue destruida por una "fuerte avenida", lo que obligó a Farjou y a Bolado a invertir varios miles de pesos en su reconstrucción. ${ }^{41}$ Juan Bautista Rincón, por su parte, logró ampliar el sistema de riego de su hacienda de Ojuelos mediante la construcción de la presa de La Estrella y de los tanques de Dolores, Atencio y La Colorada. ${ }^{42}$

La otra excepción sería la presa de Valerio, en tierras de Ciénega de Mata, construida durante el siglo XVIII y mejorada sensiblemente por don José María Rincón Gallardo durante la primera mitad del XIX. ${ }^{43}$ La obra es más importante todavía por la ubicación estratégica de la cortina y el óptimo aprovechamiento de los pequeños escurrimientos que bajaban de los cerros de alrededor. Los agrimensores

\footnotetext{
${ }^{38}$ R. Arellano, Memoria Administrativa, 1895-1899, p. XXXI.

${ }^{39}$ AHEA-FPN, Not. Aniceto Lomelí, 1907, 80, s.f.; Not. José María González, 1907, 71, 114-125.

${ }^{40}$ En su estado actual es la tercera más grande del estado, con una capacidad de 16.5 millones de metros cúbicos, suficientes para irrigar 1,400 hectáreas. (Sintesis geográfica de Aguascalientes, p. 75.)

${ }^{41}$ AHEA-FPN, Not. Candelario Medina, 1886, 50, 59-60.

${ }^{42} \mathrm{Ma}$. Guadalupe Serna Pérez, "Del mayorazgo colonial a la hacienda porfiriana: el caso de Santa Elena de Ojuelos, Jalisco", Relaciones, núm. 19, pp. 34-35.

${ }^{43}$ Por desgracia, en el archivo personal del general José María Rincón Gallardo no se conservan documentos referidos a la construcción de esta presa. Don Jaime Rincón, dueño actual del casco de la hacienda de Ciénega de Mata y bisnieto del general, supone que se construyó a fines del siglo XVIII y que su bisabuelo se encargó de mejorarla, elevar su cortina y construir el sistema de canales con que figura la presa en los inventarios de las haciendas de Ciénega de Mata que se hicieron en 1861.
} 
que en 1861 se entregaron a la tarea de inventariar las haciendas del mayorazgo calificaron esta obra de "magnífica" y le asignaron un valor de 30 mil pesos, "a más del recargo que se ha dado a los terrenos de riego". Era tan importante esta mejora que se tomó la decisión de adjudicarla por mitades a las haciendas de La Troje y Ledesma, cada una de las cuales contaba con 30 caballerías de terreno de riego. ${ }^{44}$ Ello quiere decir que la presa irrigaba poco más de 2,500 hectáreas, por lo que su capacidad de almacenamiento debió ser de más de 10 millones de metros cúbicos de agua. ${ }^{45}$

\section{Pozos artesianos}

A la postre, los pozos artesianos representaron para los propietarios una inversión más rentable y útil que las viejas y costosas presas de mampostería. Por lo menos desde mediados del siglo XIX se sabía de la existencia en la región de abundantes corrientes de aguas subterráneas y se contaba con la tecnología necesaria para perforar pozos que permitieran su uso o su almacenamiento en la superficie. En opinión de muchos técnicos y propietarios esos pozos representaban el porvenir de la agricultura, ${ }^{46}$ pese a lo cual durante mucho tiempo se desestimó su uso o se hicieron perforaciones que no rindieron el provecho esperado. Ese parece haber sido el caso del pozo que en 1871 perforó Antonio Fenoll en su hacienda de San Jacinto. ${ }^{47}$

44 Véase el inventario de la hacienda de Ledesma en AHEA-FPJ, Civil, 1878, 20.

${ }^{45}$ Ello convierte la presa de Valerio (ubicada en el municipio de Ojuelos, estado de Jalisco) en la más grande de la región.

${ }^{46}$ Desde 1851 Luis de la Rosa había señalado que la aridez y la falta de agua de las haciendas norteñas podía combatirse mediante la perforación de pozos artesianos. (Observaciones sobre varios puntos concernientes a la administración pública del estado de Zacatecas, Baltimore, Juan Murphy y Cía., Impresor Librero, 1851, p. 13.)

${ }^{47}$ El Republicano, 21 de mayo de 1871. 
Contratado por el gobierno del estado, el Ing. Mariano Bárcena realizó un poco después algunos estudios y dictaminó que "las perforaciones artesianas podrán dar excelentes resultados en esta ciudad (Aguascalientes) y sus inmediaciones, aunque el aspecto del terreno hace presumir que se hallarán a una profundidad superior a 200 metros". ${ }^{48}$ Animado por este dictamen y acuciado por la necesidad de mejorar el sistema de abasto de agua potable de la ciudad, el ayuntamiento de Aguascalientes hizo enormes gastos en la perforación de un gran pozo artesiano, que no dio los resultados apetecidos. En 1901, luego de haber alcanzado con los barrenos una profundidad de 600 metros, las obras fueron abandonadas definitivamente. ${ }^{49}$ Este estrepitoso fracaso parece haber retrasado durante varias décadas el aprovechamiento intensivo de las aguas freáticas.

Como era de esperarse, los nuevos intentos fueron costeados por los grandes propietarios. Los peritajes eran claros en lo tocante a la existencia de mantos subterráneos en toda la región, pero la experiencia del pozo perforado en la ciudad de Aguascalientes desalentaba a cualquiera. Pablo de la Arena, dueño de la hacienda del Saucillo, y Antonio Morfín Vargas, de La Cantera, fueron al parecer los primeros en hacer nuevos intentos de este tipo. Sólo que esta vez no se contrató a la Star Drilling Machine, la empresa que había fracasado con su pozo estéril de 600 metros, sino que se rentó maquinaria Parker Rotary, del tipo de la que usaba en sus pozos la compañía de petróleo El Águila. Los resultados de las nuevas per-

\footnotetext{
${ }^{48}$ El Republicano, 6 de abril de 1873. (Una referencia moderna al propósito y el valor de los estudios de Bárcena puede verse en Carlos Ortega, Estudio geoeconómico de Aguascalientes, p. 61.)

${ }^{49}$ Jesús Gómez Serrano, Aguascalientes en la historia, 1786-1920, México, Gobierno del Estado de Aguascalientes/Instituto Mora, 1988, tomo III: Sociedad y cultura, pp. 124-128.
} 
foraciones fueron àsombrosos, pues en sólo 3 días y medio de trabajo se alcanzó una profundidad de 96 metros y el agua brotó..$^{50}$

Con ese método se perforaron exitosamente pozos artesianos en las haciendas de Bóvedas, La Cantera y El Saucillo..$^{51}$ El que había en esta última daba 1,600 litros de agua por minuto (96 metros cúbicos de agua en una hora), lo que le confería a la mejora una capacidad de irrigación muy superior a la de las antiguas y costosas presas. ${ }^{52}$ Estas primeras experiencias entusiasmaron a los directivos de la Cámara Agrícola, quienes concluyeron, tal vez con demasiada rapidez, que los pozos artesianos protegerían eficazmente a los propietarios "de las veleidades e incertidumbres del temporal". La experiencia demostraba que el agua artesiana era abundante y que el éxito de las perforaciones era prácticamente seguro. El entusiasmo se extendió entre los propietarios, muchos de los cuales estaban dispuestos a rentar o comprar la maquinaria necesaria para hacer sus propios pozos, pero la Revolución interrumpió todos los trabajos y las haciendas de Bóvedas, La Cantera y El Saucillo eran a mediados de 1911 las únicas que contaban con estas mejoras. ${ }^{53}$

50 "La irrigación en nuestro estado", en Boletín mensual de la Cámara Agrícola Nacional de Aguascalientes, tomo I, núm. 2, 1 de mayo de 1911, pp. 9-10.

51 "El estado y la ciudad de Aguascalientes", en El Clarín, 10 de abril de 1909.

52 Jesús Rodríguez (editor), Directorio comercial de Aguascalientes, Aguascalientes, 1908, p. 2. (Trabajando 8 horas al día, este pozo daba en 8 días tanta agua como la que tenía, llena a su máxima capacidad, la presa de la hacienda.)

${ }^{53}$ Véase de nuevo el artículo "La irrigación en nuestro estado", ya citado en la nota 50. Fue hasta 1950, con la expansión de la agricultura comercial, cuando se comenzaron a aprovechar en forma intensa las aguas subterráneas. En 1980 se calculaba que la extracción anual alcanzaba los 340 millones de metros cúbicos, lo que ya preludiaba el problema del abatimiento de esos depósitos, que con el paso de los años se ha agudizado en forma alarmante. (Datos del Atlas geohidrológico -1978- de la Secretaría de Agricultura y Recursos Hidráulicos citados en la Sintesis geográfica de Aguascalientes, p. 24.) 


\section{La presa de Santiago}

A fines de 1895, acuciado por la falta de lluvias y la pérdida total de las cosechas, el gobernador Rafael Arellano revivió el viejo proyeto de construir una presa sobre el curso bajo del río Santiago, en tierras de la hacienda de Pabellón. Se trataba de levantar una pared de mampostería en una profunda garganta formada por el cauce del propio río. Siendo una obra tan importante y costosa, lejos del alcance de un solo propietario, el gobernador pensó que era necesario reunir entre los inversionistas los recursos y hacer de la presa el pilar que estaba exigiendo el desarrollo agrícola del valle de Aguascalientes. Arellano era no sólo un buen gobernante, atento a las necesidades más importantes del estado, sino un empeñoso hacendado que sentía en carne propia la necesidad de una mejora como esa.

En 1896 las lluvias volvieron a escasear y la ruina más completa se abatió sobre la mayor parte de las negociaciones agrícolas de la región, lo que le dio al proyecto de la presa de Santiago un carácter de urgencia. A fines de noviembre de ese año el gobernador en persona encabezó una comisión que recorrió el lugar y escuchó las explicaciones de los técnicos sobre el potencial emplazamiento de la cortina. El Ing. Tomás Medina Ugarte, a cuya ciencia fue confiado en su fase inicial este proyecto, dijo que el vaso de la presa formaría un "inmenso depósito" que proporcionaría riego abundante y seguro a una gran cantidad de ranchos y haciendas ubicados en el valle de Aguascalientes. ${ }^{54}$

Durante 1897 se llevaron a cabo diversos estudios, de los cuales se dedujo que la presa sería capaz de contener 45 millones de metros cúbicos de agua, con los que sería posible regar casi 10 mil hectáreas. La cortina de la presa se levantaría en la llamada boquilla del Paixtle, muy cerca del lindero que dividía las haciendas de Pabe-

${ }^{54}$ El Republicano, 13 de diciembre de 1896. 
llón y de Santiago, y tendría en su parte central una altura de más de 50 metros. En resumen, se trataba de una obra colosal que beneficiaría a muchas de las haciendas más importantes de la región y permitiría que la agricultura progresara en la misma medida en la que, gracias a la fundición de los Guggenheim y otros establecimientos, lo estaba haciendo la industria. El gobernador Arellano y sus consejeros creían posible reunir entre los capitalistas los 300 mil pesos que se necesitaban para acometer ese proyecto. Sin duda se trataba de una inversión que se multiplicaría gracias a la elevación del valor de la tierra, a la futura abundancia de las cosechas y a las seguridades de las que disfrutaría la agricultura, que por fin estaría a salvo de las inclemencias del temporal..$^{55}$

Sin embargo, el tiempo transcurrió sin que se reunieran los recursos necesarios para emprender esa obra. En su último informe Arellano dijo con cierto desencanto que a pesar de que los estudios habían demostrado sobradamente "la posibilidad y conveniencia de emprender esa grande obra", nada se había podido hacer todavía "debido a la falta del capital suficiente" ${ }^{56}$ Convencido tal vez de que se trataba de un proyecto que rebasaba las posibilidades de los hombres de negocios de la localidad, Arellano obtuvo en junio de 1899, casi al término de su gestión, un decreto del congreso que lo facultaba para contratar la construcción de la presa con la compañía que, asociados con Ramiro Elorduy, iban a organizar en la ciudad de México 2 personajes muy bien conocidos en Aguascalientes: los exgobernadores Alejandro Vázquez del Mercado e Ignacio T. Chávez. ${ }^{57}$

${ }_{55}$ Aparte del artículo "Un gran proyecto en vías de realizarse", publicado en $\mathrm{El}$ Republicano, 3 de octubre de 1897, pueden verse los informes del Ing. Medina Ugarte, publicados por el gobernador Carlos Sagredo en su Memoria Administrativa, 1899-1903, apéndices 61 a 64, pp. 178-190.

${ }^{56}$ Rafael Arellano, Memoria Administrativa, 1895-1899, pp. XXX-XXXI.

${ }^{57}$ Decreto 972, del 16 de junio de 1899, en El Republicano, 18 de junio de 1899. 
Arellano siempre fue un hombre prudente y tal vez por lo mismo no utilizó ese decreto, pues un contrato de concesión podía con cierta facilidad ir a parar a manos poco escrupulosas, que hicieran del asunto de la presa materia de especulación. De hecho, durante la administración de Carlos Sagredo (1899-1903) nada se hizo al respecto y en su informe final de labores el gobernador se limitó a decir que, de construirse, la presa de Santiago se asociaría sin duda al "porvenir de nuestra agricultura" ${ }^{58}$ Era un hecho unánimemente reconocido que la agricultura había experimentado una sensible mejoría gracias a la elevación del precio de los cereales y a las facilidades que daban los modernos medios de comunicación, pero en forma igualmente unánime se lamentaba la falta de grandes obras de riego, que serían las únicas capaces de transformar los "campos estériles y desiertos" en "regiones fértiles y productivas", lo que a su vez permitiría imprimirle al desarrollo agrícola un dinamismo similar al que conocían en esos momentos la industria, la minería y el comercio. ${ }^{59}$

\section{¿Político o empresario?}

Lo que aparentemente nadie alcanzó a preveer es que Vázquez del Mercado regresaría a la gubernatura en diciembre de 1903 y que, animado por alguno de sus consejeros, consideraría vigente el decreto 972, el mismo que no se había atrevido a usar Rafael Arellano. Maniobrando con una falta evidente de tacto y ante la complacencia del Congreso, en donde nadie tuvo el valor de cuestionar la vigencia de un decreto que no había sido utilizado en la época de su expedición, Vázquez del Mercado, Ignacio T. Chávez y Ramiro Elorduy le traspasaron a Edward Cook, un norteamericano que llegó a

${ }^{58}$ C. Sagredo, Memoria Administrativa, 1899-1903, p. 21.

${ }^{59}$ AHEA-FPL, 51, 171, 7.

104 ( 
Aguascalientes atraído por el auge industrial y la posibilidad de hacer a su sombra grandes negocios, los "derechos" que les daba el decreto 972. Claro está que no se trataba de una cesión gratuita ni, en rigor, de poner en pie el proyecto largamente acariciado de la presa de Santiago, sino de especular con una concesión del legislativo. En el contrato que se firmó con Cook, en efecto, éste se obligó a entregarles a los cedentes, "como único precio del traspaso, dos quintas partes de las acciones que le correspondan y que obtenga de la compañía que por sus gestiones está para constituirse". ${ }^{60}$

Casi en seguida, actuando esta vez como titular del poder ejecutivo, Vázquez del Mercado celebró con Cook un contrato tendiente a la construcción de la presa de Santiago. Aparte de ser reconocido oficialmente como dueño de los derechos para construir la presa, Cook se llevó a su casa un ventajoso contrato que no contenía precisiones técnicas ni financieras y que eximía a todos los capitales que se invirtieran en la cortina, los canales, la maquinaria "y todo lo concerniente a la instalación y explotación y conservación de la presa", del pago de cualquier impuesto durante un plazo de 30 años. ${ }^{61}$ Seguramente Cook no tenía dinero para acometer una empresa de esa magnitud, pero tenía un contrato del que con cierta habilidad él y su socio, el gobernador del estado, podían obtener un gran provecho.

En el congreso nadie se atrevió a censurar la manera de proceder del gobernador o a cuestionar la validez o la vigencia de las atribuciones de las que había hecho uso para contratar con Cook la construcción de la presa de Santiago. Sin embargo, Cook tampoco fue capaz de reunir los recursos para emprender la obra o de organizar la empresa que por su cuenta lo hiciera. A la larga, las maniobras de Vázquez del Mercado no tuvieron ninguna consecuencia de orden

\footnotetext{
${ }^{60}$ AHEA-FPN, Not. Alberto M. Dávalos, 1905, 41, 71-74.

${ }^{61}$ El contrato entre el gobernador Vázquez del Mercado y Cook se publicó en $\mathrm{El}$ Republicano, 21 de mayo de 1905.
} 
práctico y fueron sólo la innecesaria exhibición de la falta de escrúpulos con que eran capaces de proceder las autoridades. Aparentemente el gobierno no volvió a ocuparse del asunto ni el congreso se tomó la molestia de decretar formalmente la caducidad del contrato firmado con Cook, pero a fines de 1913 la Cámara Agrí́cola de Aguascalientes le solicitó a la Secretaría de Fomento una concesión para el uso de las aguas del río de Santiago, que serían represadas precisamente mediante una cortina levantada en la boquilla del Paixtle. ${ }^{62}$ Aunque tampoco esta vez la iniciativa prosperó, el hecho mismo de que la Cámara solicitara esa concesión implicaba que se consideraba caduco el contrato firmado con Cook.

Casi a título de curiosidad habría que agregar que en 1906 Vázquez del Mercado contrató con el presbítero Ramón C. Gutiérrez la construcción de otra presa, ubicada ésta en la llamada Barranca del Fuego, al poniente de la ciudad de Aguascalientes. ${ }^{63}$ Aunque se trataba de un proyecto menos ambicioso que el de la presa de Santiago, se calculaba que el vaso principal almacenaría 10 millones de metros cúbicos de agua, casi el doble de la que captaba la presa de la hacienda del Saucillo, la mayor del estado. Los primeros estudios téenicos que se hicieron despertaron muchas esperanzas, ${ }^{64}$ lo que le permitió a Gutiérrez organizar su empresa, negociar con los dueños de la hacienda de Guadalupe el derecho de inundar algunos terrenos ${ }^{65}$ y comprarles sus tierras a muchos rancheros avecindados en la estancia de los Tiscareño, que también serían afectados por el emplazamiento de la cortina y el trazo de las acequias. ${ }^{60}$

${ }^{62}$ El Republicano, 14 de diciembre de 1913.

${ }^{63}$ El contrato se publicó en El Republicano, 23 de septiembre de 1906.

or "Memoria descriptiva que presenta el Ing. Eduardo Hay sobre el proyecto de la presa que se construirá en el arroyo del Morcinique, Barranca del Fuego, para almacenar las aguas que corren por el citado arroyo y sus afluentes", en El Republicano, 31 de marzo de 1907.

${ }^{65}$ AHEA-FPN, Not. Mariano Ramos, 1906, 32, 51-52.

${ }^{66}$ AHEA-FPN, Not. Aniceto Lomelí, 1908, escrituras 10 a 20, entre las fojas 12 y 23. 
Sin embargo, el tiempo transcurrió sin que las obras dieran comienzo. Los dictámenes originales fueron rectificados y los inversionistas que en un principio habían ofrecido recursos se retractaron. El presbítero Gutiérrez alcanzó a traspasarle sus derechos a la Compañía Bancaria de Fomento y Bienes Raíces, lo que para él fue un alivio, pues recuperó por lo menos en parte el dinero que había invertido en el proyecto. Pero lo más importante es que la presa no se construyó y la agricultura se quedó esperando el momento en el que podría igualar los logros que a lo largo del Porfiriato se dieron en el terreno del desarrollo industrial y comercial.

Sería en la época del presidente Calles cuando se acometió por fin el ambicioso proyecto de construir una gran presa que irrigara todo el valle de Aguascalientes y protegiera a los agricultores de las veleidades del temporal. La idea sería entonces destruir el "control latifundista" de la región y convertir a los ejidatarios y los pequeños propietarios en artífices y beneficiarios de la estrategia de modernización agrícola alentada por el gobierno emanado de la Revolución; se trataba no sólo de estimular el desarrollo agrícola, sino también de cimentarlo sobre bases nuevas. Con una capacidad de almacenamiento de 340 millones de metros cúbicos de agua, la nueva presa convirtió en una caricatura los sueños más ardientes del gobernador Vázquez del Mercado y sus socios. Sin embargo, una compleja red de razones técnicas, económicas y políticas impidió que ese costoso megaproyecto tuviera en el desarrollo agrícola regional el gran impacto preconizado por sus impulsores. ${ }^{67}$

${ }^{67}$ Los resultados que se obtuvieron con esa estrategia, tanto en el terreno de la redistribución de la tierra como en el de los progresos de la agricultura, son evaluados por Edgar Hurtado en su trabajo ya citado. 
